\title{
Prenatal Exposure to Maternal Cigarette Smoking, Amygdala Volume, and Fat Intake in Adolescence
}

\author{
Amirreza Haghighi, MD; Deborah H. Schwartz, MA; Michal Abrahamowicz, PhD; Gabriel T. Leonard, PhD; \\ Michel Perron, PhD; Louis Richer, PhD; Suzanne Veillette, PhD; Daniel Gaudet, MD, PhD; Tomáš Paus, MD, PhD; \\ Zdenka Pausova, MD
}

\begin{abstract}
Confext: Prenatal exposure to maternal cigarette smoking is a well-established risk factor for obesity, but the underlying mechanisms are not known. Preference for fatty foods, regulated in part by the brain reward system, may contribute to the development of obesity.
\end{abstract}

Objective: To examine whether prenatal exposure to maternal cigarette smoking is associated with enhanced fat intake and risk for obesity, and whether these associations may be related to subtle structural variations in brain regions involved in reward processing.

Design: Cross-sectional study of a population-based cohort.

Setting: The Saguenay Youth Study, Quebec, Canada.

Participants: A total of 378 adolescents (aged 13 to 19 years; Tanner stage 4 and 5 of sexual maturation), half of whom were exposed prenatally to maternal cigarette smoking (mean [SD], 11.1 [6.8] cigarettes/d).

Main Outcome Measures: Fat intake was assessed with a 24-hour food recall (percentage of energy intake con- sumed as fat). Body adiposity was measured with anthropometry and multifrequency bioimpedance. Volumes of key brain structures involved in reward processing, namely the amygdala, nucleus accumbens, and orbitofrontal cortex, were measured with magnetic resonance imaging.

Results: Exposed vs nonexposed subjects exhibited a higher total body fat (by approximately $1.7 \mathrm{~kg} ; P=.009$ ) and fat intake (by $2.7 \% ; P=.001$ ). They also exhibited a lower volume of the amygdala (by $95 \mathrm{~mm}^{3} ; P<.001$ ) but not of the other 2 brain structures. Consistent with its possible role in limiting fat intake, amygdala volume correlated inversely with fat intake $(r=-0.15 ; P=.006)$.

Conclusions: Prenatal exposure to maternal cigarette smoking may promote obesity by enhancing dietary preference for fat, and this effect may be mediated in part through subtle structural variations in the amygdala.

JAMA Psychiatry. 2013;70(1):98-105.

Published online September 3, 2012.

doi:10.1001/archgenpsychiatry.2012.1101
Author Affiliations are listed at the end of this article.

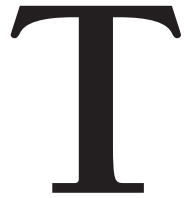

HE GROWING PREVALENCE OF obesity is a major public health concern in most industrialized countries. Prenatal exposure to maternal cigarette smoking (PEMCS) is a likely contributor to this problem, as PEMCS is a wellestablished risk factor for obesity, ${ }^{1-9}$ and a significant proportion of the current population has been exposed in utero to maternal cigarette smoking. For example, in Canada and the United States, close to 40\% of pregnant women smoked in the 1960s and 1970 s, and $10 \%$ of pregnant women still smoke at present (eFigure 1, http://www .jamapsych.com.).

The mechanisms of PEMCS-related risk for obesity are not known. Maternal smoking may affect the fetus in several ways:
(1) Inhaled nicotine induces vasoconstriction of the uteroplacental vasculature that leads to uteroplacental underperfusion and, in turn, decreased flow of nutrients and oxygen to the fetus. (2) Increased levels of carboxyhemoglobin reduce tissue oxygenation of the fetus. (3) Nicotine suppresses the mother's appetite, leading to poor nutrition of the mother and fetus. (4) Nicotine causes alterations in the cellular growth and activity of the central and peripheral nervous systems ${ }^{10}$; it passes easily through the placenta to the fetal circulation and stimulates, with inappropriate timing and intensity, the nicotinic acetylcholine receptors expressed in the developing central nervous system. ${ }^{11,12}$

Obesity develops as a result of a chronic energy imbalance in which energy intake 
exceeds energy expenditure. Excess dietary fat may contribute to this imbalance and development of obesity, ${ }^{13-15}$ as fat compared with other macronutrients (ie, carbohydrates and protein) is of higher energy density and efficiency. ${ }^{16}$ Dietary preference for fat is a complex behavior regulated by (1) homeostatic mechanisms involving brain structures such as the brainstem and hypothalamus, which serve to maintain energy balance, and (2) reward-related mechanisms involving brain structures such as the amygdala, nucleus accumbens, and orbitofrontal cortex (OFC), which process the hedonic properties of food independently of the body's energy status. ${ }^{17}$ The latter structures also process the hedonic properties of drugs of abuse ${ }^{18}$; in this context, it is of note that PEMCS has been associated with structural changes in the brain reward system ${ }^{19,20}$ and an increased rate of experimentation with drugs of abuse in childhood, adolescence, and adulthood. ${ }^{19,21-23}$

We have shown previously that PEMCS enhances accelerated weight gain during late puberty, increasing both whole-body and intra-abdominal adiposity. ${ }^{7}$ The aim of our study was to investigate whether this PEMCS-related risk for obesity is associated with enhanced dietary intake of fat and with structural variations in brain regions involved in processing rewards. The study was conducted in a population-based sample of 378 adolescents studied in late puberty in whom fat intake was assessed with a 24-hour recall performed by a qualified nutritionist, and volumetric measurements of the key structures of the brain reward system, namely the amygdala, nucleus accumbens, and OFC, ${ }^{24}$ were made with magnetic resonance imaging.

\section{METHODS}

\section{PARTICIPANTS}

We studied 378 adolescents aged 13 to 19 years who were recruited through regional high schools from the genetic founder population living in the Saguenay Lac St. Jean region of the Canadian province of Quebec, as part of the ongoing Saguenay Youth Study. ${ }^{25}$ One of the hallmarks of puberty is an accelerated weight gain that occurs in most boys and girls at Tanner stages 4 and 5 of pubertal development. ${ }^{26}$ Given our previous findings of the association between PEMCS and obesity during late (Tanner stages 4 and 5) but not early (Tanner stages 2 and 3) puberty, ${ }^{7}$ only adolescents at stages 4 and 5 were examined in the present study.

Adolescents exposed $(n=180)$ and nonexposed $(n=198)$ prenatally to maternal cigarette smoking were matched at recruitment by maternal education and participant's school attended to minimize the potentially confounding influence of socioeconomic status (SES). ${ }^{25}$ Being exposed was defined as having a mother who smoked more than 1 cigarette per day during the second trimester of pregnancy and being nonexposed was defined as having a mother who did not smoke 1 year before (and throughout) the pregnancy. With these selection criteria, all mothers of exposed participants reported smoking throughout all 3 trimesters of pregnancy. The information on maternal cigarette smoking during pregnancy was ascertained from the mother using a structured telephone interview at the time of our study and was subsequently validated against medical records from the time of pregnancy in a subset of 260 adolescents; Kappa statistics with a mean [SD] value of 0.69 [0.04] indicated a good strength of agreement in this subset (good agreement, $>0.6$ to 0.8$).{ }^{27}$ The main exclusion criteria were (1) premature birth ( $<35$ weeks) or detached placenta, (2) maternal alcohol abuse during pregnancy, (3) positive medical history of the participant for type 1 diabetes mellitus and heart disease requiring surgery or sustained medication, and (4) contraindications of magnetic resonance imaging. Additional details of recruitment have been described elsewhere. ${ }^{25}$ Written consent of the parents and assent of the adolescents were obtained. The research ethics committee of the Chicoutimi Hospital approved the study.

\section{OUTCOMES AND POTENTIAL CONFOUNDERS}

Twenty-four-hour food recall was used to obtain information on the foods and drinks consumed during the past 24 hours in a structured interview conducted in person by a trained nutritionist on a Saturday during a hospital session of our protocol. A 24-hour food recall is a well-established method of assessing diet used, for example, in the US National Health and Nutrition Examination Surveys, the only nationally representative dietary survey in the United States. ${ }^{28,29}$ The obtained information on the foods and drinks consumed during the past 24 hours was then analyzed with the recipe file to obtain energy and macronutrients (ie, fat, carbohydrates, and protein) intake. This instrument has been validated for Quebec youth. ${ }^{30}$ The proportions of energy consumed in the form of fat, carbohydrates, and protein, as well as total energy intake were calculated. In addition, the 24-hour food recall was complemented by participants' answers to 6 questions about their eating habits and fruit/vegetable consumption (in the last 7 days); these questions were selected from the Santé Québec Nutrition Survey of Quebec Youth. ${ }^{30}$

\section{ANTHROPOMETRY AND MULTIFREQUENCY BIOIMPEDANCE}

Weight (0.1-kg precision) and height (1-mm precision) were measured. Total body fat was assessed using multifrequency bioimpedance analysis (Xitron Technologies), as reported previously. ${ }^{31}$ Adolescents were asked to abstain from caffeine, alcohol, and vigorous activity 24 hours before the measurement, which was made after a 20-minute stabilization period during which the participants rested in a supine position.

\section{MAGNETIC RESONANCE IMAGING OF THE BRAIN}

Magnetic resonance T1-weighted images (1-mm isotropic) of the brain were acquired on a Phillips 1-T superconducting magnet (Gyroscan NT; Philips Healthcare). The details of magnetic resonance imaging data collection were reported previously. ${ }^{25}$ Volumes of the whole brain and of the right and left amygdala, nucleus accumbens, and OFC were obtained with FreeSurfer version 5 (FreeSurfer) ${ }^{32}$ Briefly, FreeSurfer is a collection of image-analysis algorithms that assigns automatically anatomic labels to each voxel of the magnetic resonance volume; this is achieved by combining probabilistic information about the global location of a structure in the atlas space with local spatial relationships between adjacent structures. ${ }^{33}$ In this manner, we obtained the volumes of subcortical structures examined here, namely the left and right amygdala and the left and right nucleus accumbens. In addition, FreeSurfer consists of a set of automated tools for recovering the geometry and topology of the pial surface and the gray/white interface of the left and right hemispheres. The total surface area of a particular cortical region can be estimated as a sum of verti- 


\begin{tabular}{|c|c|c|c|}
\hline \multirow[b]{2}{*}{ Characteristic } & \multicolumn{2}{|c|}{ Mean (SD) } & \multirow{2}{*}{$\underset{\text { Value }^{b}}{P}$} \\
\hline & Nonexposed & Exposed & \\
\hline \multicolumn{4}{|l|}{ Current } \\
\hline Sex, No. & & & 69 \\
\hline Males & 71 & 61 & \\
\hline Females $^{c}$ & 127 & 119 & \\
\hline Age, y & $15.6(1.8)$ & $15.8(1.7)$ & .19 \\
\hline Height, cm & $165.1(8.7)$ & $164.7(8.2)$ & .60 \\
\hline Tanner puberty stage, No. & & & .13 \\
\hline 4 & 149 & 123 & \\
\hline $5^{c}$ & 49 & 57 & \\
\hline Physical activity, No. of sessions/last $7 \mathrm{~d}$ & $3.8(2.1)$ & $3.6(2.3)$ & .34 \\
\hline Family income, Can\$/y & $55644(22325)$ & 52017 (24 214) & .13 \\
\hline \multicolumn{4}{|l|}{ Perinatal } \\
\hline Gestation length, wk & $39.1(1.5)$ & $39.3(1.4)$ & .29 \\
\hline Birth weight, g & $3503(453)$ & 3202 (464) & $<.001$ \\
\hline Breastfeeding length, wk & $9.4(11.9)$ & $4.9(9.0)$ & $<.001$ \\
\hline
\end{tabular}

Abbreviation: Can\$, Canadian dollar.

a Nonadjusted means (SD) and proportions are shown for individuals exposed and nonexposed prenatally to maternal cigarette smoking.

b $P$ values indicate statistical significance of differences between nonexposed and exposed individuals evaluated with 2 -sided $t$ test or, when appropriate, with $\chi^{2}$ statistic.

${ }^{\mathrm{C} E v a l u a t e d ~ w i t h} \chi^{2}$ statistic.

ces having the same anatomic label, while the cortical thickness is measured as the mean difference between the position of equivalent vertices in the pial and gray/white surfaces for the same cortical region. What we define in this study as the OFC, FreeSurfer classified as the lateral OFC. ${ }^{34}$ Based on the anatomic parcellation of the OFC by Chiavaras et $a l,{ }^{35}$ we defined the OFC as including the anterior, medial, and posterior OFCs but excluding the adjacent gyrus rectus (defined by FreeSurfer as the medial OFC) and the lateral orbital gyrus (defined by FreeSurfer as the pars orbitalis). The latter 2 FreeSurferbased segments extend beyond the OFC onto other frontal areas on the medial and lateral convexities. In the analyses reported here, we used the total (left + right) volumes of the 3 brain structures.

\section{QUESTIONNAIRES TO PARTICIPANTS ON PHYSICAL ACTIVITY AND PUBERTY STAGE}

Physical activity was assessed with a questionnaire validated for Quebec youth ${ }^{30}$ that asked about the number of 20-minute exercise sessions they completed in the previous 7 days. In addition, participants completed a self-report of pubertal development using the Puberty Development Scale, ${ }^{36}$ which was validated previously against physician ratings of pubertal development ${ }^{37}$; this is an 8-item self-report measure of physical development based on the Tanner stages with separate forms for males and females. For this scale, there are 5 stages of pubertal status: (1) prepubertal, (2) beginning pubertal, (3) midpubertal, (4) advanced pubertal, and (5) postpubertal. Participants answer questions about their growth in stature and pubic hair, as well as menarche in females and voice changes in males.

\section{QUESTIONNAIRES TO PARTICIPANTS ON CIGARETTE SMOKING, ALCOHOL USE, AND DRUG EXPERIMENTATION}

Adolescents were asked 15 questions about the use of alcohol, cigarettes, marijuana, and other illicit drugs, namely stimulants, psychedelics, phencyclidine, ecstasy (street name for 3,4methylenedioxymethamphetamine), prescription drugs, inhal- ers, cocaine, opiates, tranquilizers, heroin, anabolic steroids, and other drugs; these questions had been used previously ${ }^{38}$ and, for this study, were incorporated in the GRIPado (Groupe de recherche sur l'inadaptation psychosociale chez l'enfant [Research Unit on Children's Psychosocial Maladjustment]) questionnaire. The outcome measure was the sum of positive answers to the 15 questions regarding lifetime history of drug use. As part of the same questionnaire, the participants were also asked questions on cigarette smoking and alcohol use in the previous 30 days.

\section{QUESTIONNAIRES TO PARENTS ON CURRENT FAMILY SES AND PARTICIPANTS' PERINATAL FACTORS}

Parents completed questionnaires ascertaining information on SES (current family income), as well as pregnancy and early postnatal environment (birth weight and duration of breastfeeding in weeks). The questionnaire was administered by a research nurse during a home visit as described previously. ${ }^{25}$

\section{STATISTICAL METHODS}

Descriptive statistics used to characterize the study population included means and standard deviations for continuous variables and proportions for categorical variables. The main analyses focused on examining putative associations between PEMCS (exposed prenatally to maternal cigarette smoking vs nonexposed) and main outcomes: (1) total body fat, (2) dietary fat intake (percentage of 24-hour energy intake consumed as fat), and (3) total volumes of the 3 brain regions (the amygdala, nucleus accumbens, and OFC). These analyses relied on the multivariate linear model. For each outcome, we examined the normality assumption and the values of outcomes with substantial positive skewness, namely body weight, body mass index (BMI, calculated as weight in kilograms divided by height in meters squared), and total body fat were log transformed. In all analyses, we adjusted for sex (males=0, females $=1$ ), age, and, if appropriate, height (model 1). In addition, we assessed to what extent the putative associations of PEMCS with outcomes might be mediated by 
Table 2. Adiposity, Fat Preference, and the Brain Reward-Related Structures in Adolescents Nonexposed and Exposed Prenatally to Maternal Cigarette Smoking ${ }^{a}$

\begin{tabular}{|c|c|c|c|c|c|c|c|c|}
\hline \multirow[b]{2}{*}{ Outcome } & \multicolumn{2}{|c|}{ Means } & \multicolumn{2}{|l|}{ Model $1^{\mathrm{b}}$} & \multicolumn{2}{|l|}{ Model $2^{c}$} & \multicolumn{2}{|l|}{ Model $3^{d}$} \\
\hline & Nonexposed & Exposed & $\begin{array}{l}\text { Difference, Exposed vs } \\
\text { Nonexposed } \\
(95 \% \mathrm{CI})\end{array}$ & $P$ Value & $\begin{array}{l}\text { Difference, Exposed vs } \\
\text { Nonexposed } \\
(95 \% \mathrm{Cl})\end{array}$ & $P$ Value & $\begin{array}{l}\text { Difference, Exposed vs } \\
\text { Nonexposed } \\
(95 \% \mathrm{CI})\end{array}$ & $P$ Value \\
\hline \multicolumn{9}{|l|}{$\begin{array}{l}\text { Adiposity, anthropometry, and } \\
\text { multifrequency bioimpedance }\end{array}$} \\
\hline Body weight, $\mathrm{kg}^{\mathrm{e}}$ & 59.6 & 61.1 & $0.03(-0.0$ to 0.06$)$ & .10 & 0.04 (0.0 to 0.07$)$ & .04 & $0.03(0.0$ to 0.07$)$ & .06 \\
\hline BMI & 21.7 & 22.5 & $0.03(0.0$ to 0.06$)$ & .05 & 0.04 (0.0 to 0.07$)$ & .02 & 0.04 (0.0 to 0.07$)$ & .03 \\
\hline Total body fat, $\mathrm{kg}^{\mathrm{e}}$ & 12.8 & 14.7 & $0.1(0.0$ to 0.2$)$ & .009 & $0.1(0.0$ to 0.3$)$ & .01 & $0.1(0.0$ to 0.2$)$ & .03 \\
\hline \multicolumn{9}{|l|}{$\begin{array}{l}\text { Macronutrient preferences and } \\
\text { energy intake, 24-h recall }\end{array}$} \\
\hline Fat intake (\% of energy) & 30.4 & 33.1 & 2.7 (1.1 to 4.3$)$ & .001 & 3.4 (1.6 to 5.2$)$ & $<.001$ & $3.4(1.6$ to 5.2$)$ & $<.001$ \\
\hline $\begin{array}{l}\text { Carbohydrate intake ( } \% \text { of } \\
\text { energy) }\end{array}$ & 54.3 & 52.3 & $-2.0(-3.9$ to -0.0$)$ & .05 & $-3.3(-5.5$ to -1.2$)$ & .002 & $-3.3(-5.4$ to -1.1$)$ & .003 \\
\hline Protein intake (\% of energy) & 15.0 & 14.4 & $-0.6(-1.4$ to 0.3$)$ & .17 & $-0.2(-1.2$ to 0.7$)$ & .62 & $-0.2(-1.1$ to 0.7$)$ & .66 \\
\hline Energy intake, kcal & 2306 & 2449 & $150(-7$ to 308$)$ & .06 & 180 (4 to 356$)$ & .04 & $176(-0$ to 354$)$ & .05 \\
\hline \multicolumn{9}{|l|}{$\begin{array}{l}\text { Brain reward-related structures, } \\
\text { magnetic resonance imaging }\end{array}$} \\
\hline $\begin{array}{l}\text { Total amygdala volume, } \\
\mathrm{mm}^{3}\end{array}$ & 3038 & 2933 & $-95(-150$ to -40$)$ & $<.001$ & $-66(-126$ to -5$)$ & .03 & $-67(-130$ to -6$)$ & .03 \\
\hline Total NAc volume, $\mathrm{mm}^{3}$ & 1240 & 1196 & $-39(-71$ to -6$)$ & .02 & $-22(-58$ to 13$)$ & .22 & $-21(-57$ to 16$)$ & .26 \\
\hline Total OFC volume, $\mathrm{mm}^{3}$ & 17533 & 17369 & $44(-329$ to 417$)$ & .82 & $162(-250$ to 576$)$ & .44 & $145(-270$ to 561$)$ & .49 \\
\hline Total brain volume, $\mathrm{cm}^{3}$ & 1210 & 1196 & $-11(-29$ to 6$)$ & .21 & $0(-19$ to 20$)$ & .97 & 1 (-18 to 21$)$ & .89 \\
\hline
\end{tabular}

Abbreviations: BMI, body mass index (calculated as weight in kilograms divided by height in meters squared); NAc, nucleus accumbens; OFC, orbitofrontal cortex. a Nonadjusted means and adjusted differences with $95 \%$ confidence intervals (Cl) are presented for individuals exposed and nonexposed prenatally to maternal cigarette smoking. The differences between exposed and nonexposed individuals were adjusted for potential confounders in the 3 models.

${ }^{b}$ Model 1: sex + age + (height, when appropriate).

${ }^{\mathrm{C}}$ Model 2: sex + age + (height, when appropriate) + birth weight + breastfeeding duration + gestation duration.

d Model 3: sex + age + (height, when appropriate) + birth weight + breastfeeding duration + gestation duration + family income.

${ }^{\mathrm{e}}$ Adjusted differences were calculated with log-transformed values.

PEMCS associations with lower birth weight and a shorter period of breastfeeding. ${ }^{39,40}$ To this end, we repeated the analyses of main outcomes with additional adjustment for birth weight, duration of gestation, and duration of breastfeeding (model 2). We also examined whether the putative associations of PEMCS with outcomes might be mediated by lower SES with additional adjustment for current family income (model 3). However, note that exposed and nonexposed individuals were matched by maternal education during ascertainment; therefore, we did not observe any significant differences between the 2 groups in SES (Table 1). Furthermore, we examined whether the putative associations of PEMCS with outcomes might be mediated by maternal obesity, an important risk factor for offspring obesity $^{41}$; an additional adjustment was made for maternal BMI (model 4). Moreover, we explored whether the putative associations of PEMCS with outcomes are present across the entire range of adiposity. To address this question, we assessed the associations in individuals with above median and below median BMI. The median split was performed separately in exposed and nonexposed individuals on age-adjusted and sexadjusted BMI. With a path analysis, we also examined whether variations in brain regions associated with reward processing impacted adiposity (ie, BMI) by way of higher fat intake. This analysis was conducted separately in exposed and nonexposed individuals and only for the brain region that showed a significant association with fat intake in models 1-4 (ie, the amygdala). Finally, supplementary analyses focused on examining putative associations of PEMCS with cigarette smoking, alcohol intake, and drug experimentation. All hypotheses were tested using 2-tailed tests at $\alpha=0.05$. All analyses but the path analysis, which was performed using $\mathrm{R}$ version 2.14 (R Project for Statistical Computing), were carried out with JMP version 8.02 (SAS Institute Inc).

\section{RESULTS}

On average, mothers of exposed participants smoked a mean (SD) of 11.1 [6.8] cigarettes per day throughout their pregnancies (eTable 1). Exposed compared with nonexposed adolescents did not differ by sex, age, puberty stage, or height (Table 1 ). They also did not vary in physical activity and family income (Table 1) or in their eating habits such as having dinner with the family, alone, or with friends (eTable 2). As expected, ${ }^{42}$ exposed vs nonexposed individuals were lighter at birth (by $301 \mathrm{~g}$; $P<.001)$ and were breastfed for a shorter period of time (by 4.5 weeks; $P<.001$; Table 1 ).

\section{PEMCS AND OBESITY}

Exposed vs nonexposed adolescents had a marginally higher body weight (by approximately $1.7 \mathrm{~kg} ; P=.10$ ) and BMI (by approximately $0.7 \mathrm{~kg} / \mathrm{m}^{2} ; P=.05$ ) and a significantly higher total body fat (approximately by $1.7 \mathrm{~kg}$; $P=.009$; Table 2). These differences were present while adjusting for a basic set of potential confounders, namely age, sex, and, when appropriate, height (body weight and total body fat). Importantly, they remained virtually unchanged after additional adjusting for variables frequently associated with maternal cigarette smoking during pregnancy and implicated on their own in increasing the risk for obesity (ie, lower birth weight, shorter duration [or lack of] breastfeeding, and lower SES) $)^{39,40,43}$ 


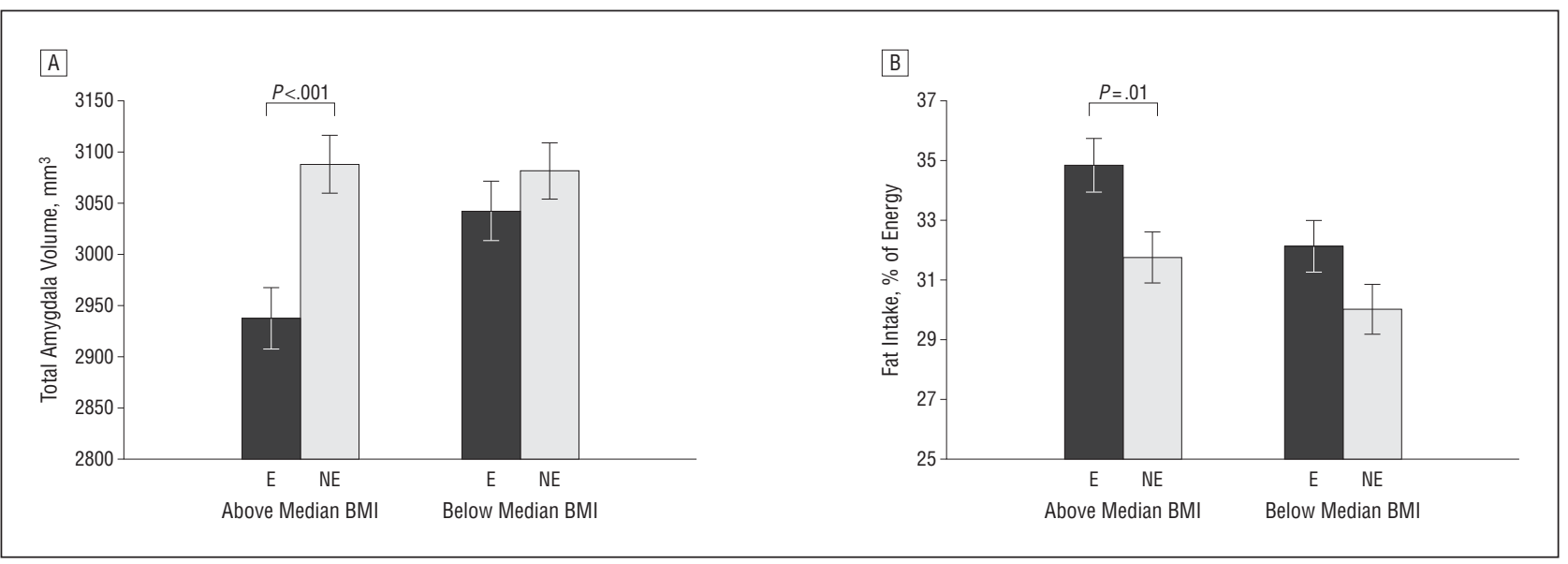

Figure. Association of prenatal exposure to maternal cigarette smoking with amygdala volume $(A)$ and fat intake (B) in individuals with above median and below median body mass index (BMI). The median split was performed separately in exposed (E) and nonexposed (NE) individuals on age-adjusted and sex-adjusted BMI. The data are presented as age-adjusted and sex-adjusted means and standard deviations.

(models 2 and 3 in Table 2). They also remained virtually unchanged after additional adjusting for maternal BMI, a known risk factor for offspring obesity ${ }^{41}$ (model 4 in eTable 3). Thus, it appears that the association between PEMCS and greater adiposity is independent of these factors and, as such, may be specific to maternal cigarette smoking. The exposure-associated differences in adiposity (higher by $13 \%$ in exposed vs nonexposed individuals) is likely clinically relevant, as previous research showed that a difference of $9 \%$ of total body fat is associated with a significantly higher risk for the metabolic syndrome in adolescents. ${ }^{44}$

\section{PEMCS AND FAT INTAKE}

In addition to higher adiposity, exposed vs nonexposed participants showed higher intake of fat, expressed as percentage of energy intake consumed in the form of fat (by $+2.7 \% ; P=.001$; Table 2$)$. This difference remained highly significant $(P<.001$; Table 2$)$ when adjusted also for the previously mentioned perinatal and socioeconomic factors (ie, birth weight, breastfeeding, and family income) and maternal BMI (Table 2 and models 2-4 in eTable 3). Furthermore, consistent with the possibility that greater fat intake increases the risk for obesity, fat intake correlated modestly with total body fat in the whole sample $(r=0.13 ; P<.02)$, with similar trends being observed in exposed $(r=0.14 ; P=.06)$ and nonexposed $(r=0.11$; $P=.17)$ participants.

Apart from fat intake, exposed vs nonexposed participants showed tendencies toward higher energy intake (by $+150 \mathrm{kcal} ; P=.06)$ and lower carbohydrate intake (by $-2 \%$; $P=.05)$ but no difference in protein intake $(P=.17$; Table 2$)$. These differences in energy, carbohydrate, and protein intake became significant when adjusted for perinatal and socioeconomic factors and maternal BMI (models 2 and 3 in Table 2, and model 4 in eTable 3).

\section{PEMCS AND THE BRAIN}

Exposed vs nonexposed participants demonstrated significantly smaller amygdala volume (by $95 \mathrm{~mm}^{3} ; P<.001$;
Table 2); this difference remained significant when adjusted for perinatal and socioeconomic factors and maternal BMI (models 2 and 3 in Table 2, and model 4 in eTable 3 ). In addition, amygdala volume correlated inversely with fat intake $(r=-0.15 ; P=.006)$, and this correlation was seen in exposed $(r=-0.16 ; P<.04)$ but not in nonexposed $(r=-0.08 ; P=.29)$ participants.

Furthermore, exposed vs nonexposed participants showed a moderately lower volume of the nucleus accumbens (by $39 \mathrm{~mm}^{3} ; P=.02$ ), but this difference became nonsignificant when adjusted for perinatal and socioeconomic factors and maternal BMI (Table 2 and eTable 3). No differences were observed in volumes of the OFC and the whole brain (Table 2 and eTable 3 ).

Moreover, exposed vs nonexposed individuals demonstrated lower amygdala volume and higher fat intake only among individuals with above median BMI (obese) and not among individuals with below median BMI (Figure), indicating that the nonobese subset of exposed individuals might be protected from the adverse outcomes of the exposure.

Finally, we tested the hypothesized relationships between lower amygdala volume, higher fat intake, and higher adiposity with a path analysis. In exposed individuals, this model provided good fit $\left(\chi_{1}^{2}=0.01 ; P=.92\right.$; root mean square error of approximation $=0 ; 90 \% \mathrm{CI}$, 0-0.07; comparative fit index $=1)$, but in nonexposed individuals, the model provided poor fit $\left(\chi_{1}^{2}=1.36 ; P=.24\right.$; root mean square error of approximation $=0.04 ; 90 \% \mathrm{CI}$, $0-0.20$; comparative fit index $=0.74$ ). In exposed individuals, smaller amygdala volume predicted higher fat intake $(P=.03)$, while higher fat intake showed a trend toward higher BMI $(P=.06)$, whereas in nonexposed individuals, smaller amygdala volumes did not predict higher fat intake $(P=.27)$, and higher fat intake did not predict higher BMI $(P=.18$; eFigure 2$)$.

\section{PEMCS AND CIGARETTE SMOKING, ALCOHOL INTAKE, AND DRUG EXPERIMENTATION}

Exposed vs nonexposed participants showed higher alcohol use and drug experimentation but not cigarette 
smoking, and these differences remained essentially unchanged when adjusted for perinatal and socioeconomic factors (eTable 4). Alcohol intake and drug experimentation did not correlate with amygdala volume, indicating that the exact mechanisms of PEMCS associations with these behaviors may not be the same as those underlying the association between PEMCS and fat preference. In addition, amygdala volume remained significantly lower in exposed vs nonexposed individuals after adjusting not only for age and sex but also for cigarette smoking (number of cigarettes per day in the last 30 days; $P=.001$; estimated mean difference $=93$ [95\% CI, 37$148 \mathrm{~mm}^{3}$ ), alcohol intake (number of days drinking in the last 30 days; $P<.001$; estimated difference $=101[95 \%$ CI, 45-157] $\mathrm{mm}^{3}$ ), or drug experimentation (number of drugs tried in life; $P=.002$; estimated mean difference $=88$ [95\% CI, 32-143] $\mathrm{mm}^{3}$ ).

\section{COMMENT}

The results of our study suggest that PEMCS may increase the risk for obesity by enhancing dietary intake of fat, and that this effect may be mediated in part through subtle changes in brain structures involved in reward processing.

Prenatal exposure to maternal cigarette smoking is a well-established risk factor for obesity, ${ }^{1-7}$ but the underlying mechanisms are not known. Our study suggests that PEMCS-induced modifications of the neural pathways enhancing preference for fat may represent one such mechanism. Although not yet reported in the context of PEMCS, enhanced preference for fat has been observed previously in association with another prenatal factor, namely maternal undernutrition during gestation. ${ }^{45}$ Both maternal malnutrition ${ }^{39}$ and cigarette smoking during pregnancy ${ }^{46}$ are adverse intrauterine environments leading to fetal growth restriction, which itself is a strong predictor of future obesity. ${ }^{39,40}$ For this reason, we also tested to what extent the association of PEMCS with fat preference might be mediated by PEMCS-related low birth weight (model 2). This analysis showed that, after adjusting for birth weight, the association between PEMCS and preference for fat remained highly significant $(P<.001$; Table 2$)$, thus suggesting that PEMCS may enhance preference for fat independently of birth weight through mechanisms specific to cigarette smoking. This is also suggested by previous epidemiologic research reporting that the PEMCS association with obesity is independent of birth weight. ${ }^{47,48}$

Diets high in fat are considered highly rewarding. ${ }^{49,50}$ The hedonic properties of fat are processed by similar structures of the brain reward system as the hedonic properties of drugs of abuse. ${ }^{18}$ Animal research suggests that prenatal exposure to nicotine, the main psychoactive compound in cigarette smoke, causes long-term changes in the developing brain and in the brain reward system in particular. Acting on the nicotinic cholinergic receptors, nicotine modulates the release of neurotransmitters (eg, dopamine) within the brain reward system. ${ }^{51}$ Studies in adolescent rats demonstrated that prenatal exposure to nicotine reduces both expression of the nico- tinic cholinergic receptors ${ }^{52}$ and nicotine-stimulated neurotransmitter release in this system. ${ }^{53}$ Moreover, nicotine exerts trophic effects during brain development, ${ }^{54}$ and prenatal exposure to nicotine has been shown to cause subtle structural changes in the brain..$^{55}$ In our study, exposed vs nonexposed individuals exhibited lower amygdala volume and the amygdala volume correlated inversely, albeit modestly, with fat preference. The amygdala is a structure of the brain reward system studied extensively in the context of both drug addiction and the regulation of fat preference. With respect to the former, lower amygdala volume has been observed in individuals with alcohol addiction ${ }^{56}$ in whom it was associated with greater alcohol craving and more likely relapse into alcohol consumption. ${ }^{57}$ Lower amygdala volume has also been observed in adolescent and young-adult offspring of individuals with alcohol addiction, suggesting that it may be a risk factor for alcohol addiction rather than its consequence. ${ }^{58}$ With respect to the regulation of fat preference, activation of the amygdala by intra-amygdalar administrations of neuropeptide $\mathrm{Y}^{59}$ and enterostatin ${ }^{60}$ decreases preference for fat in experimental animals. Taken together, the current research indicates that reduced size and/or lesser activation of the amygdala may increase the risk for addiction and augment fat preference. These observations are consistent with the possible role of the PEMCS-induced reduction of the amygdala size in increasing fat preference and in turn the risk for obesity, as suggested by the results of this study.

In our study, exposed vs nonexposed individuals showed lower amygdala volume by $66 \mathrm{~mm}^{3}$ to $95 \mathrm{~mm}^{3}$. Although this is a relatively subtle difference, it could translate into meaningful differences in the number of neurons and possibly function. For example, it has been shown that the (right) posterodorsal subnucleus of the rat amygdala (at postnatal day 26) is larger in males than females by approximately $0.042 \mathrm{~mm}^{3}$ (total volume of $0.258 \mathrm{~mm}^{3}$ in juvenile males) and that volumetric difference is largely due to a higher number of neurons (by 5471 neurons). ${ }^{61}$ Nevertheless, future functional imaging studies in humans and preclinical studies in animal models are required to further our understanding of how the exposure impacts the amygdala and the reward aspects of fat intake.

In our study, we observed that only about half of the exposed individuals showed significantly lower amygdala volume and higher fat intake (Figure). The vulnerability of these individuals may in part be due to their genetic makeup. It may be mediated by genes that change expression/function in response to the exposure (geneenvironment interactions), and by genes that are shared between the mother and offspring and play a role in increasing both the mother's inability to quit smoking during pregnancy and the offspring's preference for fat and obesity (gene-environment correlations). To dissect these complexities, further large-scale studies into the genetic underpinnings of brain structure and behavior are required, and these studies need to be conducted not only in exposed/nonexposed individuals but also in their parents.

Hedonic properties of food are considered the main driving force behind food choices. ${ }^{62}$ Other factors, such 
as eating habits, culture, economics, and availability, also play a role. ${ }^{62}$ In our study, both exposed and nonexposed individuals were drawn from the genetic founder population of the Saguenay Lac St. Jean region of the Canadian province of Quebec; this population is characterized by a relatively high genetic and cultural homogeneity. ${ }^{25}$ In addition, exposed and nonexposed individuals were matched at recruitment by maternal education; as a result of this design, exposed and nonexposed participants did not differ by current family income, a key index of SES (Table 1). Furthermore, exposed and nonexposed participants did not differ by obesogenic behaviors such as a lack of family meals (eTable 2 ). They also did not differ in the frequency of consuming fruits and vegetables, although consistent with their higher intake of fat and lower intake of carbohydrates, exposed vs nonexposed subjects showed trends toward eating fruits and vegetables less frequently; these trends remained unchanged when additionally adjusted for family income, suggesting they were not due to socioeconomic disparities (eTable 2).

In summary, the results of our study are consistent with the fetal-programming hypothesis of obesity ${ }^{39,63}$ and suggest that PEMCS may contribute in this context by modifying fat intake through neural mechanisms involving the amygdala.

Submitted for Publication: March 12, 2012; final revision received May 31, 2012; accepted June 27, 2012.

Published Online: September 3, 2012. doi:10.1001/ archgenpsychiatry.2012.1101

Author Affiliations: The Hospital for Sick Children (Drs Haghighi and Pausova), Rotman Research Institute (Ms Schwartz and Dr Paus), University of Toronto, Toronto; Department of Epidemiology, Biostatistics, and Occupational Health (Dr Abrahamowicz), Montreal Neurological Institute (Drs Leonard and Paus), McGill University, Montreal; Ecogene-21 Clinical Research Center and Lipid Clinic, Department of Medicine, Université de Montréal, Chicoutimi Hospital (Dr Gaudet), Québec; Groupe ÉCOBES, Recherche et transfert, Cégep de Jonquière, Jonquière (Drs Perron and Veillette); and Université du Québec à Chicoutimi (Dr Richer), Canada.

Correspondence: Zdenka Pausova, MD, The Hospital for Sick Children, University of Toronto, 555 University Ave, Toronto M5G 1X8, Canada (zdenka.pausova@sickkids .ca).

Author Contributions: Dr Pausova had full access to all of the data in the study and takes responsibility for the integrity of the data and the accuracy of the data analysis.

Financial Disclosure: None reported.

Funding/Support: The Saguenay Youth Study is funded by the Canadian Institutes of Health Research (Drs Pausova and Paus), the Heart and Stroke Foundation of Quebec (Dr Pausova), and the Canadian Foundation for Innovation (Dr Pausova). Dr Abrahamowicz is a James McGill professor of biostatistics at McGill University. Dr Paus is the Tanenbaum chair in population neuroscience at the Rotman Research Institute, University of Toronto.

Online-Only Material: The eTables and eFigures are available at http://www.jamapsych.com.
Additional Contributions: We thank the following individuals for their contributions in acquiring data: Manon Bernard, MSc (database architect, The Hospital for Sick Children), Jacynthe Tremblay, RN, and her team of research nurses (Saguenay Hospital), Helene Simard, MA, and her team of research assistants (Cégep de Jonquière), and Rosanne Aleong, $\mathrm{PhD}$ (program manager, Rotman Research Institute).

\section{REFERENCES}

1. Power C, Jefferis BJ. Fetal environment and subsequent obesity: a study of maternal smoking. Int J Epidemiol. 2002;31(2):413-419.

2. von Kries R, Toschke AM, Koletzko B, Slikker W Jr. Maternal smoking during pregnancy and childhood obesity. Am J Epidemiol. 2002;156(10):954-961.

3. Oken E, Huh SY, Taveras EM, Rich-Edwards JW, Gillman MW. Associations of maternal prenatal smoking with child adiposity and blood pressure. Obes Res. 2005;13(11):2021-2028.

4. Leary SD, Smith GD, Rogers IS, Reilly JJ, Wells JC, Ness AR. Smoking during pregnancy and offspring fat and lean mass in childhood. Obesity (Silver Spring). 2006;14(12):2284-2293.

5. Al Mamun A, Lawlor DA, Alati R, O'Callaghan MJ, Williams GM, Najman JM. Does maternal smoking during pregnancy have a direct effect on future offspring obesity? evidence from a prospective birth cohort study. Am J Epidemiol. 2006;164(4):317-325.

6. Oken E, Levitan EB, Gillman MW. Maternal smoking during pregnancy and child overweight: systematic review and meta-analysis. Int J Obes (Lond). 2008; 32(2):201-210.

7. Syme C, Abrahamowicz M, Mahboubi A, Leonard GT, Perron M, Richer L, Veillette S, Gaudet D, Paus T, Pausova Z. Prenatal exposure to maternal cigarette smoking and accumulation of intra-abdominal fat during adolescence. Obesity (Silver Spring). 2010;18(5):1021-1025

8. Power C, Atherton K, Thomas C. Maternal smoking in pregnancy, adult adiposity and other risk factors for cardiovascular disease. Atherosclerosis. 2010; 211(2):643-648.

9. Toschke AM, Montgomery SM, Pfeiffer U, von Kries R. Early intrauterine exposure to tobacco-inhaled products and obesity. Am J Epidemiol. 2003;158(11): 1068-1074.

10. Slotkin TA. Fetal nicotine or cocaine exposure: which one is worse? J Pharmacol Exp Ther. 1998;285(3):931-945.

11. Dwyer JB, McQuown SC, Leslie FM. The dynamic effects of nicotine on the developing brain. Pharmacol Ther. 2009;122(2):125-139.

12. Gotti C, Zoli M, Clementi F. Brain nicotinic acetylcholine receptors: native subtypes and their relevance. Trends Pharmacol Sci. 2006;27(9):482-491.

13. Klesges RC, Klesges LM, Haddock CK, Eck LH. A longitudinal analysis of the impact of dietary intake and physical activity on weight change in adults. Am J Clin Nutr. 1992;55(4):818-822.

14. Tucker LA, Seljaas GT, Hager RL. Body fat percentage of children varies according to their diet composition. J Am Diet Assoc. 1997;97(9):981-986.

15. Bray GA, Popkin BM. Dietary fat intake does affect obesity! Am J Clin Nutr. 1998; 68(6):1157-1173.

16. Tappy L. Thermic effect of food and sympathetic nervous system activity in humans. Reprod Nutr Dev. 1996;36(4):391-397

17. Kenny PJ. Reward mechanisms in obesity: new insights and future directions. Neuron. 2011;69(4):664-679.

18. Kenny PJ. Common cellular and molecular mechanisms in obesity and drug addiction. Nat Rev Neurosci. 2011;12(11):638-651.

19. Lotfipour S, Ferguson E, Leonard G, Perron M, Pike B, Richer L, Séguin JR, Toro $R$, Veillette S, Pausova Z, Paus T. Orbitofrontal cortex and drug use during adolescence: role of prenatal exposure to maternal smoking and BDNF genotype. Arch Gen Psychiatry. 2009;66(11):1244-1252.

20. Lotfipour S, Leonard G, Perron M, Pike B, Richer L, Séguin JR, Toro R, Veillette S, Pausova Z, Paus T. Prenatal exposure to maternal cigarette smoking interacts with a polymorphism in the alpha6 nicotinic acetylcholine receptor gene to influence drug use and striatum volume in adolescence. Mol Psychiatry. 2010; 15(1):6-8.

21. Weissman MM, Warner V, Wickramaratne PJ, Kandel DB. Maternal smoking during pregnancy and psychopathology in offspring followed to adulthood. $J \mathrm{Am}$ Acad Child Adolesc Psychiatry. 1999;38(7):892-899.

22. Al Mamun A, O'Callaghan FV, Alati R, O'Callaghan M, Najman JM, Williams GM, Bor W. Does maternal smoking during pregnancy predict the smoking patterns of young adult offspring? a birth cohort study. Tob Control. 2006;15(6):452-457. 
23. Buka SL, Shenassa ED, Niaura R. Elevated risk of tobacco dependence among offspring of mothers who smoked during pregnancy: a 30-year prospective study. Am J Psychiatry. 2003;160(11):1978-1984.

24. Schultz W. Multiple reward signals in the brain. Nat Rev Neurosci. 2000;1(3):199 207.

25. Pausova Z, Paus T, Abrahamowicz M, Almerigi J, Arbour N, Bernard M, Gaudet D, Hanzalek P, Hamet P, Evans AC, Kramer M, Laberge L, Leal SM, Leonard G, Lerner J, Lerner RM, Mathieu J, Perron M, Pike B, Pitiot A, Richer L, Séguin JR, Syme C, Toro R, Tremblay RE, Veillette S, Watkins K. Genes, maternal smoking, and the offspring brain and body during adolescence: design of the Saguenay Youth Study. Hum Brain Mapp. 2007;28(6):502-518.

26. Rogol AD, Roemmich JN, Clark PA. Growth at puberty. J Adolesc Health. 2002; 31(6)(suppl):192-200.

27. Landis JR, Koch GG. The measurement of observer agreement for categorical data. Biometrics. 1977;33(1):159-174.

28. Thompson FES. A.F. Dietary assessment methodology. In: Bousky C, ed. Nutrition in the Prevention and Treatment of Disease. 2nd ed. San Diego, California: Academic Press; 2008.

29. Buzzard IM, Faucett CL, Jeffery RW, McBane L, McGovern P, Baxter JS, Shapiro AC, Blackburn GL, Chlebowski RT, Elashoff RM, Wynder EL. Monitoring dietary change in a low-fat diet intervention study: advantages of using 24-hour dietary recalls vs food records. J Am Diet Assoc. 1996;96(6):574-579.

30. Berthiaume $P$, Lavalee $C$, Villeneuve $M$, Vigneaut $M$. Enquête sociale et de santé auprès des enfants et des adolescents québécois [in French]. In: Volet Nutrition. Québec, Canada: Les Publications du Québec; 2004:19-33.

31. Syme C, Abrahamowicz M, Leonard GT, Perron M, Richer L, Veillette S, Xiao Y, Gaudet D, Paus T, Pausova Z. Sex differences in blood pressure and its relationship to body composition and metabolism in adolescence. Arch Pediatr Adolesc Med. 2009;163(9):818-825

32. Fischl B, Dale AM. Measuring the thickness of the human cerebral cortex from magnetic resonance images. Proc Natl Acad Sci U S A. 2000;97(20):1105011055.

33. Fischl B, Salat DH, Busa E, Albert M, Dieterich M, Haselgrove C, van der Kouwe A, Killiany R, Kennedy D, Klaveness S, Montillo A, Makris N, Rosen B, Dale AM. Whole brain segmentation: automated labeling of neuroanatomical structures in the human brain. Neuron. 2002;33(3):341-355.

34. Desikan RS, Ségonne F, Fischl B, Quinn BT, Dickerson BC, Blacker D, Buckner RL, Dale AM, Maguire RP, Hyman BT, Albert MS, Killiany RJ. An automated labeling system for subdividing the human cerebral cortex on MRI scans into gyral based regions of interest. Neuroimage. 2006;31(3):968-980.

35. Chiavaras MM, LeGoualher G, Evans A, Petrides M. Three-dimensional probabilistic atlas of the human orbitofrontal sulci in standardized stereotaxic space. Neuroimage. 2001;13(3):479-496.

36. Petersen A, Crockett L, Richards M, Boxer A. A self-report measure of pubertal status: reliability, validity, and initial norms. J Youth Adolesc. 1988;17(2):117133. doi:10.1007/BF01537962.

37. Shirtcliff EA, Dahl RE, Pollak SD. Pubertal development: correspondence between hormonal and physical development. Child Dev. 2009;80(2):327-337.

38. Zoccolillo M, Vitaro F, Tremblay RE. Problem drug and alcohol use in a community sample of adolescents. J Am Acad Child Adolesc Psychiatry. 1999;38(7): 900-907.

39. Ravelli GP, Stein ZA, Susser MW. Obesity in young men after famine exposure in utero and early infancy. N Engl J Med. 1976;295(7):349-353.

40. Parsons TJ, Power C, Logan S, Summerbell CD. Childhood predictors of adult obesity: a systematic review. Int J Obes Relat Metab Disord. 1999;23(suppl 8) :S1-S107.

41. Hochner H, Friedlander $Y$, Calderon-Margalit R, Meiner V, Sagy Y, Avgil-Tsadok M, Burger A, Savitsky B, Siscovick DS, Manor O. Associations of maternal prepregnancy body mass index and gestational weight gain with adult offspring cardiometabolic risk factors: the Jerusalem Perinatal Family Follow-up Study. Circulation. 2012;125(11):1381-1389.

42. Cnattingius $\mathrm{S}$. The epidemiology of smoking during pregnancy: smoking preva- lence, maternal characteristics, and pregnancy outcomes. Nicotine Tob Res. 2004; 6(suppl 2):S125-S140

43. Shrewsbury V, Wardle J. Socioeconomic status and adiposity in childhood: a systematic review of cross-sectional studies 1990-2005. Obesity (Silver Spring). 2008;16(2):275-284.

44. Syme C, Abrahamowicz M, Leonard GT, Perron M, Pitiot A, Qiu X, Richer L, Totman J, Veillette S, Xiao Y, Gaudet D, Paus T, Pausova Z. Intra-abdominal adiposity and individual components of the metabolic syndrome in adolescence: sex differences and underlying mechanisms. Arch Pediatr Adolesc Med. 2008; 162(5):453-461.

45. Lussana F, Painter RC, Ocke MC, Buller HR, Bossuyt PM, Roseboom TJ. Prenatal exposure to the Dutch famine is associated with a preference for fatty foods and a more atherogenic lipid profile. Am J Clin Nutr. 2008;88(6):1648-1652.

46. Kramer MS. Socioeconomic determinants of intrauterine growth retardation. Eur J Clin Nutr. 1998(52, suppl 1):S29-S32; discussion S32-S33.

47. Beyerlein A, Rückinger S, Toschke AM, Schaffrath Rosario A, von Kries R. Is Iow birth weight in the causal pathway of the association between maternal smoking in pregnancy and higher BMI in the offspring? Eur J Epidemiol. 2011;26(5): 413-420.

48. Rückinger S, Beyerlein A, Jacobsen G, von Kries R, Vik T. Growth in utero and body mass index at age 5 years in children of smoking and non-smoking mothers. Early Hum Dev. 2010;86(12):773-777.

49. De Araujo IE, Rolls ET. Representation in the human brain of food texture and oral fat. J Neurosci. 2004;24(12):3086-3093.

50. Rolls ET. Taste, olfactory and food texture reward processing in the brain and obesity. Int J Obes (Lond). 2011;35(4):550. doi:10.1038/ijo.2010.155.

51. Di Chiara G. Role of dopamine in the behavioural actions of nicotine related to addiction. Eur J Pharmacol. 2000;393(1-3):295-314

52. Chen H, Parker SL, Matta SG, Sharp BM. Gestational nicotine exposure reduces nicotinic cholinergic receptor ( $\mathrm{AChR}$ ) expression in dopaminergic brain regions of adolescent rats. Eur J Neurosci. 2005;22(2):380-388.

53. Kane VB, Fu Y, Matta SG, Sharp BM. Gestational nicotine exposure attenuates nicotine-stimulated dopamine release in the nucleus accumbens shell of adolescent Lewis rats. J Pharmacol Exp Ther. 2004;308(2):521-528.

54. Slotkin TA. Cholinergic systems in brain development and disruption by neurotoxicants: nicotine, environmental tobacco smoke, organophosphates. Toxicol Appl Pharmacol. 2004;198(2):132-151.

55. Roy TS, Sabherwal U. Effects of prenatal nicotine exposure on the morphogenesis of somatosensory cortex. Neurotoxicol Teratol. 1994;16(4):411-421.

56. Hill SY. Trajectories of alcohol use and electrophysiological and morphological indices of brain development: distinguishing causes from consequences. Ann N Y Acad Sci. 2004:1021:245-259.

57. Wrase J, Makris N, Braus DF, Mann K, Smolka MN, Kennedy DN, Caviness VS, Hodge SM, Tang L, Albaugh M, Ziegler DA, Davis OC, Kissling C, Schumann G Breiter HC, Heinz A. Amygdala volume associated with alcohol abuse relapse and craving. Am J Psychiatry. 2008;165(9):1179-1184.

58. Hill SY, De Bellis MD, Keshavan MS, Lowers L, Shen S, Hall J, Pitts T. Right amygdala volume in adolescent and young adult offspring from families at high risk for developing alcoholism. Biol Psychiatry. 2001;49(11):894-905.

59. Primeaux SD, York DA, Bray GA. Neuropeptide $Y$ administration into the amyg dala alters high fat food intake. Peptides. 2006;27(7):1644-1651

60. Boghossian S, Park M, York DA. Melanocortin activity in the amygdala controls appetite for dietary fat. Am J Physiol Regul Integr Comp Physiol. 2010;298 (2):R385-R393

61. Cooke BM, Stokas MR, Woolley CS. Morphological sex differences and laterality in the prepubertal medial amygdala. J Comp Neurol. 2007;501(6):904-915.

62. Raynor HA, Polley BA, Wing RR, Jeffery RW. Is dietary fat intake related to liking or household availability of high- and low-fat foods? Obes Res. 2004;12(5): 816-823.

63. Parsons TJ, Power C, Manor 0 . Fetal and early life growth and body mass index from birth to early adulthood in 1958 British cohort: longitudinal study. BMJ. 2001;323(7325):1331-1335. 